\title{
Altering calcium influx for selective destruction of breast tumor
}

\author{
Han-Gang Yu ${ }^{1^{*}} \mathbb{D}$, Sarah McLaughlin², Mackenzie Newman ${ }^{1}$, Kathleen Brundage ${ }^{2,3}$, Amanda Ammer ${ }^{2}$, \\ Karen Martin ${ }^{2,4}$ and James Coad ${ }^{5}$
}

\begin{abstract}
Background: Human triple-negative breast cancer has limited therapeutic choices. Breast tumor cells have depolarized plasma membrane potential. Using this unique electrical property, we aim to develop an effective selective killing of triple-negative breast cancer.

Methods: We used an engineered L-type voltage-gated calcium channel (Cec), activated by membrane depolarization without inactivation, to induce excessive calcium influx in breast tumor cells. Patch clamp and flow cytometry were used in testing the killing selectivity and efficiency of human breast tumor cells in vitro. Bioluminescence and ultrasound imaging were used in studies of human triple-negative breast cancer cell MDA-MB-231 xenograft in mice. Histological staining, immunoblotting and immunohistochemistry were used to investigate mechanism that mediates Cec-induced cell death.

Results: Activating Cec channels expressed in human breast cancer MCF7 cells produced enormous calcium influx at depolarized membrane. Activating the wild-type Cav1.2 channels expressed in MCF7 cells also produced a large calcium influx at depolarized membrane, but this calcium influx was diminished at the sustained membrane depolarization due to channel inactivation. MCF7 cells expressing Cec died when the membrane potential was held at -10 mV for $1 \mathrm{hr}$, while non-Cec-expressing MCF7 cells were alive. MCF7 cell death was 8-fold higher in Cec-expressing cells than in non-Cec-expressing cells. Direct injection of lentivirus containing Cec into MDA-MB-231 xenograft in mice inhibited tumor growth. Activated caspase-3 protein was detected only in MDA-MB-231 cells expressing Cec, along with a significantly increased expression of activated caspase-3 in xenograft tumor treated with Cec.
\end{abstract}

Conclusions: We demonstrated a novel strategy to induce constant calcium influx that selectively kills human triple-negative breast tumor cells.

Keywords: Breast cancer, Triple-negative, Bioelectricity, Calcium channel, Selective killing, Caspase-3

\section{Background}

One of the biggest challenges in breast cancer treatment is the non-selective destruction of healthy cells alongside cancer cells. There are three major clinically identifiable types of breast cancer: estrogen receptor $(E R+)$ and/or progesterone receptor $(\mathrm{PR}+)$ positive, human epidermal growth factor receptor 2 amplified (HER2-amplified), and triple-negative (no alterations of ER, PR, and HER2). The intracellular signaling pathways that underlie these subtypes of breast cancer are different and as a result

\footnotetext{
* Correspondence: hyu@hsc.wvu.edu

'Department of Physiology and Pharmacology, West Virginia University, One Medical Center Drive, Morgantown, WV 26506, USA

Full list of author information is available at the end of the article
}

chemotherapeutics that target one pathway will be effective in only some of the breast cancer subtypes [1].

Altered bioelectricity during cell division, embryogenesis, and development has been recognized [2]. In vivo impedance measurement of female breasts with and without tumors revealed lower resistance in malignant tumors than in normal mammary tissues [3]. In excised normal and malignant breast tissues, the conductivity is higher in malignant tissues [4]. In breast tissue cells from patients with infiltrating ductal carcinoma, the resting membrane potential $(\mathrm{Em})$ was found to be $-13 \mathrm{mV}$, independent of estrogen receptor (ER) or progesterone receptor (PR) presence [5]. Normal human breast epithelial cell Em is near $-60 \mathrm{mV}[5]$. 
Calcium influx has increasingly been recognized to play a critical role in breast cancer [6]. Cell proliferation depends on external $\mathrm{Ca}^{2+}$, and a fine-controlled $\mathrm{Ca}^{2+}$ influx through voltage-gated calcium channel (VGCC) is a critical signal in cell proliferation $[7,8]$. Under physiological conditions, there exists a 20,000 - fold $\mathrm{Ca}^{2+}$ ion gradient across plasma membrane $\left(\left[\mathrm{Ca}^{2+}\right]_{0}\right.$ is close to $2 \mathrm{mM},\left[\mathrm{Ca}^{2+}\right]_{\mathrm{i}}$ is around $\left.100 \mathrm{nM}\right)[9]$. Thus, calcium influx via VGCC becomes a critical cell signal for a variety of cell functions such as neurotransmission, muscle contraction and cell growth [10].

VGCC have been categorized into Cav1 family (L-type), Cav2 family (N-, P/Q and R-type), and Cav3 family (T-type), based on their biophysical, pharmacological and structural properties [10]. VGCC are found in excitable cells such as neuronal, skeletal muscle and cardiac cells, but are not present in non-excitable healthy human mammary epithelial cells [11]. In primary tumor from patients and breast cancer cell lines Cav3.2 transcripts and protein expression have been detected [12-14]. Cav3 Ttype calcium channels have a much faster inactivation compared to Cav1 L-type channels [10]. The brief calcium influx through Cav3.2 T-type channel inactivation in response to depolarization is an essential signal for breast cancer cell growth since blockade of this T-type channel dramatically reduced proliferation of breast cancer cells [14].

The amount of calcium ions entering cells is tightly controlled by voltage-dependent activation and inactivation of VGCC $[15,16]$. Disturbance of VGCC gating can significantly change the amount of external calcium ions entering cell. Excessive $\mathrm{Ca}^{2+}$ influx has been demonstrated to induce apoptosis and cell death $[9,17,18]$. VGCC are activated by membrane depolarization [10]. However, during sustained membrane depolarization $\mathrm{Ca}^{2+}$ entry is limited by channel inactivation, an intrinsic protection mechanism $[19,20]$. When the channel inactivation is removed, continuous $\mathrm{Ca}^{2+}$ influx leading to excessive accumulation of intracellular $\mathrm{Ca}^{2+}$ ions can be generated.

We have recently demonstrated that altering bioelectricity and external calcium concentration can induce death of different types of breast cancer cells, MCF7 and MDA-MB-231 [21]. In the present work, we demonstrated that using an engineered VGCC that lacks inactivation $(\mathrm{Cec})$ [22], massive $\mathrm{Ca}^{2+}$ influx can be induced to trigger the death of human carcinoma breast tumor cells, but not in non-tumor human mammary epithelial cells. Cec injected into a human breast tumor in vivo caused cell death within the tumor via caspase- 3 and inhibited tumor growth. This approach of selective killing of human breast cancer cells is independent of $\mathrm{ER}+/ \mathrm{PR}+, \mathrm{HER} 2$ and triple-negative subtypes.

\section{Methods}

Human mammary non-tumor and cancer cell lines were purchased from American Tissue Culture Center (ATCC) (non-tumor cells MCF10A, CRL-10317; MCF7 cell line, HTB-22; MDA-MB-231 cell line: HTB-26).

\section{Cell culture and plasmid transfection}

Human breast adenocarcinoma cells (ER-positive MCF7, triple-negative MDA-MB-231/Luc) and human mammary gland epithelial cells (MCF10A) were grown in Dulbecco's modified Eagle's medium (DMEM, Invitrogen), supplemented with $10 \%$ fetal bovine serum, $100 \mathrm{IU} / \mathrm{mL}$ penicillin, and $100 \mathrm{~g} / \mathrm{L}$ streptomycin. Normal human mammary epithelial cells (HMEC) were grown in mammary epithelial cell basal medium (MEC), supplemented with MEC growth kit (ATCC). For patch clamp studies, HMEC and MCF7 cells were grown on poly-D-lysine coated coverslips in DMEM and MEC, respectively.

Cells with $50-70 \%$ confluence in 6-well plates were used for transient plasmid transfection (1-2 $\mu \mathrm{g}$ for each plasmid). We used three methods for plasmid transfection: Lipofectamine2000 transfection reagent (Invitrogen), MCF7 transfection reagent (Altogen) and Nucleofection (electroporation, Lonza).

Cav1.2 and Cec, both in pCEP4 mammalian expression vector, were either co-transfected with GFP or fused with mCherry for verification of expression and served as selection guidance for patch clamp studies and flow cytometry experiments. The beta subunit of Cav1.2, $\beta 2 \mathrm{a}$, was co-transfected with Cav1.2 and Cec to enhance the surface expression of the channel proteins [16].

\section{Patch clamp studies}

From day 1 up to day 4 post-transfected cells with green fluorescence were selected for patch clamp studies. The cells grown on coverslips were placed in a lucite bath with the temperature maintained at $35-37{ }^{\circ} \mathrm{C}$. Em and voltage-gated calcium currents were recorded using the whole cell patch clamp technique with an Axopatch700B amplifier. Em was measured with normal Tyrode and pipette solutions. The Tyrode solution contained (in $\mathrm{mM}$ ): $143 \mathrm{NaCl}$, $5.4 \mathrm{KCl}, 1.8 \mathrm{CaCl}_{2}, 0.5 \mathrm{MgCl}_{2}, 0.25$ $\mathrm{NaH}_{2} \mathrm{PO}_{4}$, and 5 HEPES; pH was adjusted to 7.4 by $\mathrm{NaOH}$. The pipette solution contained (in mM): 120 $\mathrm{KCl}, 1 \mathrm{CaCl}_{2}, 5 \mathrm{MgCl}_{2}, 5 \mathrm{Na} 2 \mathrm{ATP}, 11$ EGTA, 10 HEPES, and 11 glucose; pH was adjusted to 7.3 by $\mathrm{KOH}$.

For $\mathrm{I}_{\mathrm{CaL}}$ recordings, the pipettes had a resistance of 2-5 $\mathrm{M} \Omega$ when filled with (in $\mathrm{mM}$ ): $108 \mathrm{CsCl}, 4 \mathrm{MgCl}_{2}$, 9 EGTA, and 9 HEPES. The bath solution contained (in $\mathrm{mM}$ ): $2 \mathrm{CaCl}_{2}, 1 \mathrm{MgCl}_{2}, 10$ HEPES, 10 TEA, 10 glucose, and $100 \mathrm{CsCl}$. Both pipette and bath solutions were adjusted by $\mathrm{CsOH}$ to $\mathrm{pH}$ 7.2. $\mathrm{P} / 4$ protocols were 
used to remove the leak currents [23]. The whole-cell patch clamp data were acquired by CLAMPEX and analyzed by CLAMPFIT (pClamp 9, Molecular Device/Axon).

\section{Live cell imaging}

Live cell imaging experiments were performed using a Zeiss Axio Observer A1 inverted microscope with fluorescence. Images were acquired and analyzed using AxioVision (version 4.6). Live cell imaging with patch clamp experiments were performed using Slidebook (version 4.0). We used ethidium homodimer-1 (EthD-1, Invitrogen) dye $(0.2-0.5 \mu \mathrm{l}$ of $2 \mathrm{mM}$ stock to $1 \mathrm{ml}$ culture of cells in 6-well plate) to label dead cells. EthD-1 dye enters the cell only after the plasma membrane is disintegrated, it then binds to DNA in the nucleus and emits red fluorescence (Invitrogen) [24].

\section{Flow cytometry}

Cell death was examined using a Live/Dead Fixable Violet Viability kit (Life Technologies) following the manufacturer's instructions. Briefly, cells were transfected and cultured as described above. After trypsinization and washing, cell pellets were resuspended in PBS and stained with the Live/Dead dye in the kit. Samples were then analyzed on a BD LSRFortessa analytical flow cytometer (BD Biosciences, San Jose CA) using BD Diva 8.0 software. The GFP signal was detected using a $488 \mathrm{~nm}$ sapphire laser and a 530/30 BP filter in front of the detector. The Violet live/dead signal was detected using a $405 \mathrm{~nm}$ OBIS laser and a 450/50 BP filter in front of the detector. Between 25,000 and 30,000 events were collected for each sample.

\section{Lentivirus preparation}

Cec was inserted into a GFP tagged lentiviral vector, pCDH-CMV-MCS-EF1-GFP + Puro (System Biosciences, SBI) between SwaI and NotI in MCS to yield lenti-GFPCec plasmid. The empty lentiviral vector fused with GFP (lenti-GFP) was used as a negative control. Lentivirus was produced using pPACK lentivector packaging systems following the vendor's instruction manual (SBI). The concentration of lentivirus was $1-2 \times 10^{12} \mathrm{LP} / \mathrm{ml}$ (LP: lentiviral particle). For treatment groups, 5-10ul of lentiGFP-Cec was injected directly into the primary tumor. For control groups, 5-10ul of lenti-GFP was injected directly into the primary tumor. The same amount of virus was administrated to each group per experiment.

\section{Breast tumor induction in NOD scid gamma (NSG) mice}

Female NSG-immunodeficient mice were purchased from the Jackson Laboratory. Animals were housed in the WVU Animal Facility under protocols approved by the Institutional Animal Care and Use Committee. For mammary pad injections, pathogen-free luciferase-expressing human breast adenocarcinoma cells (MDA-MB-231/Luc, $1-2 \times 10^{6}$ cells/animal) were injected into the fourth inguinal mammary gland of 6- to 8-week-old mice. Primary tumors had formed one week of injection.

\section{Primary tumor imaging}

Animals were anesthetized by exposure to $1-3 \%$ isoflurane during imaging. Imaging was performed weekly over the course of each experiment, typically for 4-6 weeks.

Tumor size measurement by bioluminescence imaging (BLI) D-Luciferin $(150 \mathrm{mg} / \mathrm{kg})$ was injected into the peritoneum. Images were obtained after ten minutes' exposure using an IVIS Lumina-II Imaging System and Living Image-4.0 software (PerkinElmer). Luciferin-sensitive bioluminescence signals (photons/s) were used to assess the tumor size.

Tumor volume measurement by ultrasound imaging (USI) Tumor volume was imaged by Vevo2100 MicroUltrasound System. A 40 or $50 \mathrm{mHz}$ transducer was used, depending on the tumor volume. A 3-dimensional (3D) image was acquired with scanning distance of $0.071 \mathrm{~mm}$ between images. Vevo software then integrated the images into a reconstructed 3D tumor from which the tumor volume was obtained.

\section{Tumor fluorescence imaging}

Tumor imaging was performed with an Olympus MVX10 MacroView microscope in conjunction with cellSens software version 1.11. Images were acquired using a $1 \mathrm{X}$ objective at $0.8 \mathrm{X}$ zoom. Bright field images were rendered at around $20 \mathrm{~ms}$ exposure in 16-bit grayscale, while fluorescence was captured at around $700 \mathrm{~ms}$ in 8-bit RGB mode. Image overlays were converted to 8bit RGB color before analysis.

\section{Histology of NSG tumors}

Primary tumors were removed from NSG mice, fixed in $4 \%(\mathrm{~m} / \mathrm{v})$ formaldehyde for $16 \mathrm{hrs}$ and embedded in paraffin. Paraffin blocks were cut to 5 - $\mu$ m-thick sections for hematoxylin and eosin (H\&E) stain. Imaging of $\mathrm{H} \& \mathrm{E}$ slides was performed with an Olympus MVX10 MacroView microscope equipped with dual cameras, Hamamatsu (fluorescence imaging) and DP26 (color imaging). Necrotic area was quantified using Image (NIH).

\section{Western blotting}

MDA-MB-231 cells were and transfected with either a lentiviral GFP construct, wild-type Cav1.2, Cec, or empty vector as a control. After three days of incubation, adherent cells were lysed in buffer $(20 \mathrm{mM}$ Tris, $150 \mathrm{mM}$ $\mathrm{NaCl}, 10 \mathrm{mM}$ EGTA, and $10 \mathrm{mM}$ EDTA at $\mathrm{pH} \sim 7.4$ ) with a cell scraper and allowed to sit for five minutes. 
Detached cells were pelleted and resuspended in the lysis solution. After centrifugation at 3,000xg for five minutes, supernatant protein concentration was measured using Bradford's method.

SDS-PAGE was carried out in $4-12 \%$ gradient bis-tris gels (Invitrogen) on 10-20 $\mu \mathrm{g}$ of total protein. Samples were then transferred to $0.2 \mu \mathrm{m}$ pore PVDF membranes (Thermo Scientific). After blocking with 3\% BSA-V (Sigma) in TBST (Invitrogen), caspase-3 antibody (Abcam) was added in a 1:1000 dilution and left to incubate overnight at $4{ }^{\circ} \mathrm{C}$, followed by incubation with secondary antibody in a 1:5000 dilution. After one hour, membranes were washed five times for five minutes in TBST and visualized using a standard ECL kit (Life Technologies).

\section{Immunohistochemistry of NSG tumors}

Immunohistochemistry (IHC) detection of cleaved caspase3 in formalin-fixed paraffin-embedded (FFPE) tumor tissue was performed according to vendor's manual instruction (Biocare) and following a verified protocol in the Pathology Laboratory of Translational Medicine at WVU. Briefly, $3 \mu \mathrm{m}$ sections were deparaffinized on slides, quenched with hydrogen peroxide, and incubated in cleaved caspase-3 antibody (prediluted rabbit polyclonal antibody, Biocare Medical, Concord, CA, 1:200 dilution) at $4{ }^{\circ} \mathrm{C}$ for $4 \mathrm{~min}$. Horseradish peroxidase-containing secondary antibody (UMap anti-RB, Roche, Diagnostic, Cupertino, CA) was then added for $8 \mathrm{~min}$ and developed using Biocare DAB (brown color). Hematoxylin was used as a counterstain (blue color).

Caspase-3 IHC slides were examined under an Olympus AX70 Provis microscope equipped with an Optronics MicroFire color CCD camera and a 20x/0.70 UPlanApo objective or a 40x/0.90 UApo objective. Images were acquired using Stereo Investigator 10 (MDF Bioscience). Quantification of cells expressing cleaved caspase-3 was performed by ImageJ [25].

\section{Statistical analysis}

Data were shown as mean \pm standard deviation (SD) in the text. Bar figures were presented as mean $\pm \mathrm{SD}$ using GraphPad 4 (Prism). Student's $t$-test and twoway ANOVA (for more than two groups) were used for statistical analysis. $P<0.05$ was considered as statistically significant.

\section{Results}

Voltage-gated calcium currents in normal and tumor mammary epithelial cells

Patch clamp studies confirmed absence of voltage-gated calcium currents in normal HMEC cells (Fig. 1a) and only T-type voltage-gated calcium current $\left(\mathrm{I}_{\mathrm{CaT}}\right)$ in MCF7 cells (Fig. 1b). T-type calcium current was verified by its fast activation and inactivation as well as blockage by $1 \mathrm{mM} \mathrm{Mn}^{2+}$ and $0.1 \mathrm{mM} \mathrm{Ni}^{2+}$ ions $[10,26]$ (dotted line in Fig. 1b).

\section{Properties of L-type VGCC and engineered channel (Cec) expressed in MCF7 cells}

L-type calcium channels are activated at a depolarized Em, around $-40 \mathrm{mV}$ associated with 10-100 times slower inactivation compared to T-type calcium channel [10]. Cav1.2 L-type calcium channel was co-transfected with GFP into MCF7 cells. L-type calcium current $\left(\mathrm{I}_{\mathrm{CaL}}, \mathrm{I}_{\mathrm{Cav1.2}}\right)$ was elicited by a $500 \mathrm{~ms}$ depolarizing pulse to $-10 \mathrm{mV}$ (Fig. 1c). Inactivation of $\mathrm{I}_{\mathrm{CaL}}$ is significantly slower compared to that of $\mathrm{I}_{\mathrm{CaT}}$ (or $\mathrm{I}_{\mathrm{Cav} 3.1}$ ) (Fig. 1b) (note the different time scales used in $1 \mathrm{~b}$ and 1c). L-type calcium current was verified by a specific L-type calcium channel blocker, verapamil $(10 \mu \mathrm{M})$ (dotted line in Fig. 1c).

$\mathrm{Cec}$, an engineered Cav1.2 channel with defective inactivation, was expressed in MCF7 cells. Cec current $\left(\mathrm{I}_{\mathrm{Cec}}\right)$ was activated by a $500 \mathrm{~ms}$ depolarizing pulse to $-10 \mathrm{mV}$ (Fig. 1d). Cec has the same activation as Cav1.2 but lacks inactivation, i.e. the current trace does not come back to the baseline, as T-type and wild-type L-type calcium currents do. Cec channel has a similar current-voltage relationship as Cav1.2 (Fig. 1e).

Calcium influx through voltage-gated calcium channels is indicated by the gray lines enclosed by the current trace and the dotted baseline (Fig. 1b, c, d). In response to a $500 \mathrm{~ms}$ depolarizing pulse to $-10 \mathrm{mV}$ from a holding potential of $-80 \mathrm{mV}$, Cec induced more than a 50,000 -fold larger amount of calcium influx than was induced by endogenous T-type channels in MCF7 cells (Ca-flux_HMEC: $0.001 \pm 0.001 \mathrm{pA}^{*} \mathrm{~ms}$; CaT-flux_MCF7: 0.24 \pm 0.15 pA*ms; Cav1.2-flux_MCF7: $24.0 \pm 3.8$ pA*ms; Cec-flux_MCF7: $53.8 \pm 5.1$ pA*ms; Fig. 1f). Under the same pulse protocol, Cav1.2 induced more than a 20,000fold higher calcium influx compared to T-type calcium channel (Fig. 1f).

\section{Cec-induced cell death in MCF7 cells}

A dramatic increase in calcium influx is lethal to cell survival. To test whether excessive calcium influx through Cec channels can indeed trigger cell death, we activated Cec while simultaneously monitoring the cell's status using fluorescence imaging. Figure $2 \mathrm{a}$ shows a Cec-expressing MCF7 cell clamped by a patch pipette. Figure $2 \mathrm{~b}$ shows three neighboring Cec-expressing cells that were not patch clamped. Figure 2c shows the naturally dead cells stained by Ethd-1 (red color), which contrast the patched live cell shown in the white circle. After holding the cell membrane at $-10 \mathrm{mV}$ for $1 \mathrm{~h}$, the patched cell was dead as indicated by the appearance of red color (Fig. 2d). Figure 2e shows the same image with increased exposure time for clarity. Death of the patched cell was confirmed by disappearance of GFP and the 

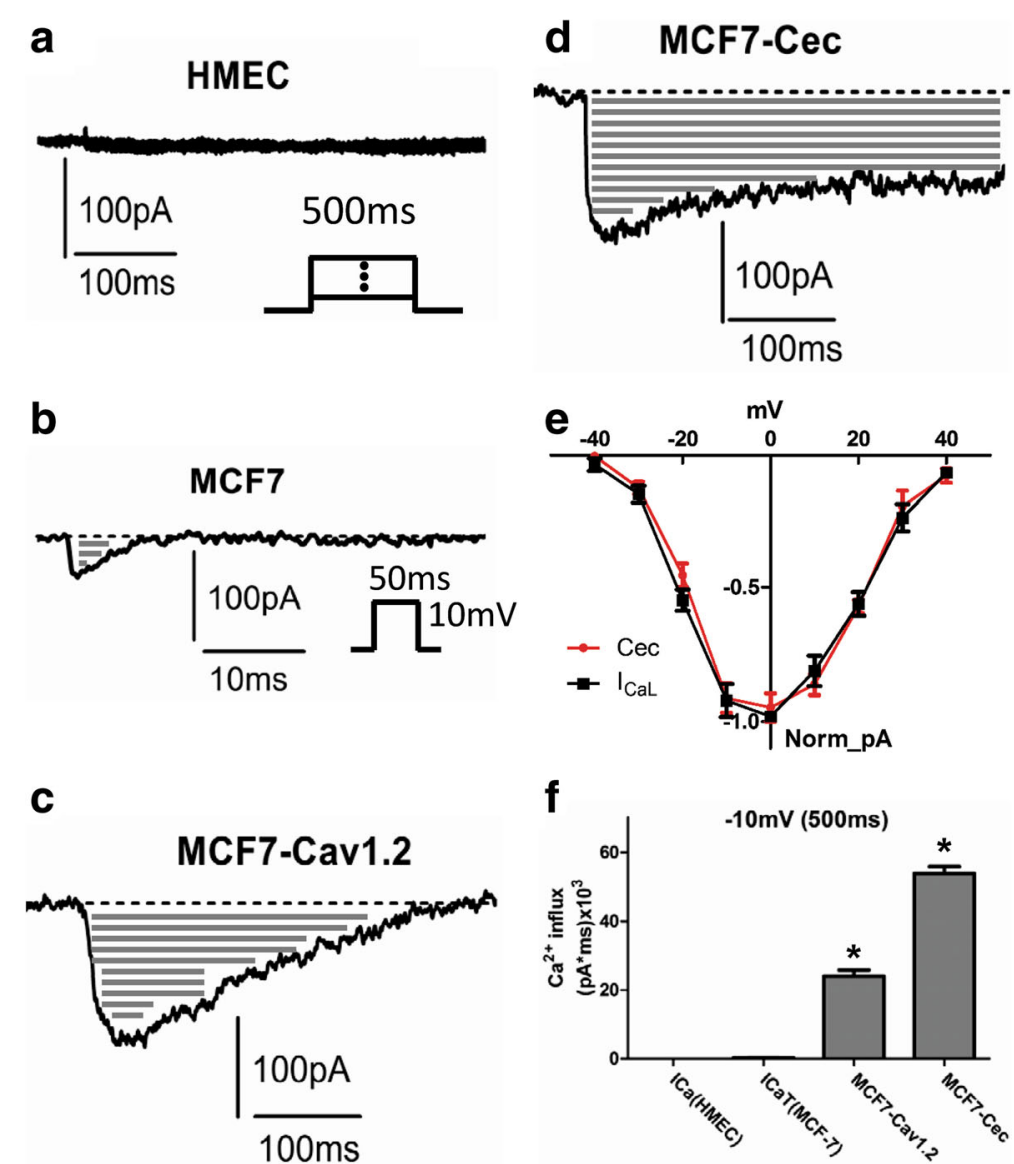

Fig. $1 \mathrm{Ca}^{2+}$ influx through L-type voltage-gated calcium channels in breast cancer cells. a Lack of voltage-gated calcium currents in response to the $500 \mathrm{~ms}$ depolarizing pulses from $-50 \mathrm{mV}$ to $+50 \mathrm{mV}$ in $10 \mathrm{mv}$ increments (inset). b Representative T-type calcium current in a MCF7 cell (inset is the pulse protocol). c After 3-day transfection of Cav1.2 in MCF7 cells, L-type calcium current was elicited by a 500 ms depolarizing pulse to -10 mV; gray lines show the $\mathrm{Ca}^{2+}$ influx. $\mathbf{d}$ After 1-day transfection of Cec, L-type calcium current was elicited by a $500 \mathrm{~ms}$ depolarizing pulse to $-10 \mathrm{mV}$. Gray lines in the enclosed area in $\mathbf{b}, \mathbf{c}$, and $\mathbf{d}$ indicate the $\mathrm{Ca}^{2+}$ influx. e Normalized current-voltage (IV) relationship of L-type Cav1.2 (I $\left.\mathrm{CaL}_{\mathrm{L}}\right)$ and Cec expressed in MCF7 cells ( $n=6$ in each group), the membrane potential was held at $-80 \mathrm{mV}$. $\mathbf{f} \mathrm{Ca}^{2+}$ influx generated by T-type calcium current, L-type calcium current, and Cec calcium current in response to a $500 \mathrm{~ms}$ depolarizing pulse to $-10 \mathrm{mV}$, respectively $(n=6) .{ }^{*}$ indicates statistical significance compare to $\mathrm{I}_{\mathrm{Ca}}$ in MCF7 and in HMEC groups. The membrane potential was held at $-80 \mathrm{mV}$

survival of its neighboring cells which also expressed Cec but were not voltage-clamped at $-10 \mathrm{mV}$ (Fig. $2 \mathrm{f}$ versus Fig. 2b). Cells co-expressing Cav1.2 and GFP under the same experimental conditions showed no sign of dying (Figs. $2 \mathrm{~g}-\mathrm{i}$ ).

To examine the efficacy of Cec-induced cell death, we compared the percent of cell death in GFP-expressing or Cec-expressing MCF7 cells using flow cytometry. After 3 days of transfection, $\mathrm{Cec}$ induced significantly more cell death (Fig. 3b) than GFP alone (Fig. 3a) in both $\operatorname{GFP}(-)$ and $\operatorname{GFP}(+)$ populations (upper left and upper right quadrants). In the absence of $\mathrm{Ca}^{2+}$ ions, the flow cytometry results were similar in Cec-expressing and non-Cec-expressing cells (Fig. 3c, d). On an average, there was a 9-fold increase in $\mathrm{GFP}(+)$ dying cells in Cecexpressing than in GFP-expressing MCF7 cells (Fig. 3e) $(\mathrm{GFP}(+)$ dead were $18.3 \pm 8.6 \%$ in Cec-expressing cells and $1.7 \pm 0.7 \%$ in GFP-expressing cells, respectively, $n=6$ ). In addition, GFP(-) cell death was increased by 8 -fold in Cec-expressing $(58.8 \pm 10.5 \%)$ than in GFP-expressing $(6.9 \pm 6.6 \%)$ MCF7 cells $(n=6)$. It should be noted that GFP(-) dead cells included both untransfected cells and Cec-expressing cells that have degraded GFP protein.

When calcium was removed from the culture medium, there was no statistically significant difference in percentage of cell death between GFP-expressing and Cecexpressing groups (Fig. 3f) $(\mathrm{GFP}(+)$ dead were $1.2 \pm 1.2 \%$ in Cec-expressing cells and $2.2 \pm 2.7 \%$ in GFP-expressing cells, $n=6)$. The percentage of cell death in GFP(-) dead in Cec-expressing cells was also significantly decreased when $\mathrm{Ca}^{2+}$ was absent $(74.7 \pm 12.7 \%$ in the presence of $\mathrm{Ca}^{2+}$ and $16.1 \pm 7.8 \%$ in the absence of $\mathrm{Ca}^{2+}, n=6$ ).

MCF10A (a non-tumorigenic human breast epithelial cell line) cells have been commonly used as a control to 


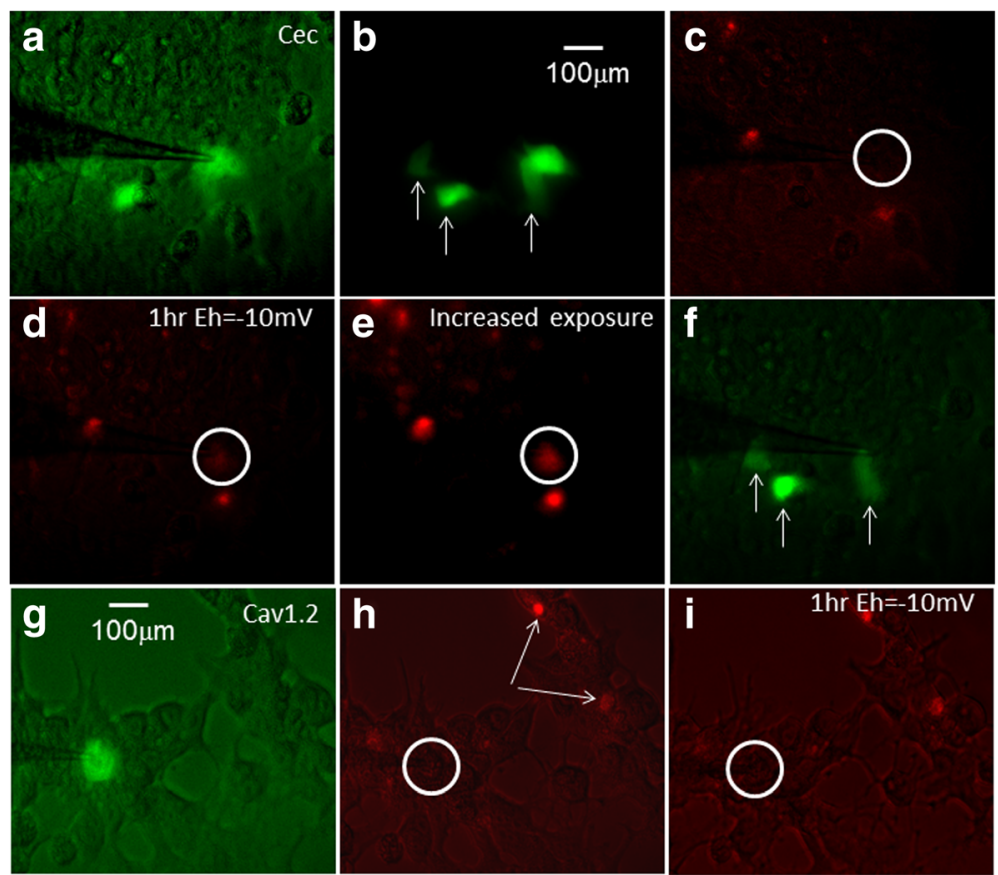

Fig. 2 Depolarization-triggered cell death in a single Cec-expressing MCF7 cell. a After 1 day transfection a Cec-expressing cell was clamped by a patch pipette. $\mathbf{b}$ A focused region of four Cec-expressing cells showing green fluorescence. $\mathbf{c}$ Ethd-1 was used to stain dead cells. Note that the patched cell in a white circle was live (no red color) prior to membrane depolarization. $\mathbf{d}$ After $1 \mathrm{~h}$ of depolarizing membrane to $-10 \mathrm{mV}$, the patched cell was dead shown by the red color in the white circle. e Enhanced exposure to illustrate the red color in the white circle. $\mathbf{f}$ In comparison to (b) the dead cell was confirmed by loss of green fluorescent signal while other 3 Cec-expressing cells not subjected to membrane depolarization were still alive. $\mathbf{g}$ A Cav1.2-expressing MCF cell patched by a patch pipette, $\mathbf{h}$ Ethd-1 demonstrated that the patched cell was alive (in the white circle), the white arrows indicated dead cells used as a reference. i After membrane depolarization to $-10 \mathrm{mV}$ for $1 \mathrm{~h}$, the cell was still alive without the red color. White circle in $\mathrm{H}$ and $\mathrm{I}$ indicates the patched cell. Similar results were obtained in an additional 5 cells

MCF7 cells [27]. We found the resting membrane potential of MCF10A to be $-53.5 \pm 8.2 \mathrm{mV}(n=4)$, in agreement with a previous report [5]. Flow cytometry results showed that in $\mathrm{Ca}^{2+}$ - containing culture medium, there is no statistically significant difference between GFPexpressing cells and Cec + GFP expressing cells (Fig. 3g). $(\mathrm{GFP}(+)$ dead were $3.7 \pm 3.1 \%$ in Cec-expressing cells and $5.3 \pm 3.0 \%$ in GFP-expressing cells, $n=3$ ).

\section{Cec-induced inhibition of tumor growth in NSG mice}

To further explore whether Cec-mediated $\mathrm{Ca}^{2+}$ influx can inhibit breast tumor growth in vivo, we used a commonly used human breast tumor mouse model, NOD scid gamma (NSG) mice. The xenograft tumors in NSG were induced by injection of MDA-MB-231/Luc cells. MDA-MB-231 is a human breast triple-negative cancer cell line [28]. The resting membrane potential was measured to be $-39.48 \pm 12.14 \quad(n=7)$, similar to MCF7. After three weeks of tumor growth, lentivirus injection was performed. Control mice were injected with lentiGFP and treatment mice were injected with lenti-GFPCec directly into the tumor. To confirm the presence of lentivirus within the tumor after injection, the primary tumor was removed and subjected to fluorescence imaging. Figure 4a shows the absence of GFP fluorescence within a tumor which received no injection of lentivirus. No GFP fluorescence was observed in tumors injected by lenti-GFP-Cec, presumably due to the cell death. Tumors injected with lenti-GFP showed GFP fluorescence (Fig. 4b, white arrow; Fig. 4c - enlarged GFP image). Similar observation was seen in at least three control mice.

Tumor size was measured by bioluminescence imaging (BLI) illustrated in 4D (control mouse) and 4E (treatment mouse). Changes BLI for control and treatment groups are shown in Fig. 4f. Lentivirus injection was performed in week 3 . There are no statistically significant changes in BLI between the two groups until week 5. At week 5 , the tumor size was $70 \%$ smaller in treatment group $(0.5 \pm 0.2$ (photons $\left./ \mathrm{s}) \times 10^{9}, n=6\right)$ compared to control group (1.69 \pm 0.79 (photons/s) $\left.\times 10^{9}, n=4, p=0.007\right)$. In treatment group, BLI was also decreased by $53 \%$ at week $5\left(0.5 \pm 0.2(\right.$ photons $\left./ \mathrm{s}) \times 10^{9}\right)$ compared to week 4 $(1.06 \pm 0.32$ (photons $\left./ \mathrm{s}) \times 10^{9}, p=0.015\right)$.

Figure 5 shows the tumor volume measured by ultrasound imaging (USI). For the first four weeks there are no statistical differences in tumor volumes between the control and treatment groups $(p>0.05)$. At week 5, 

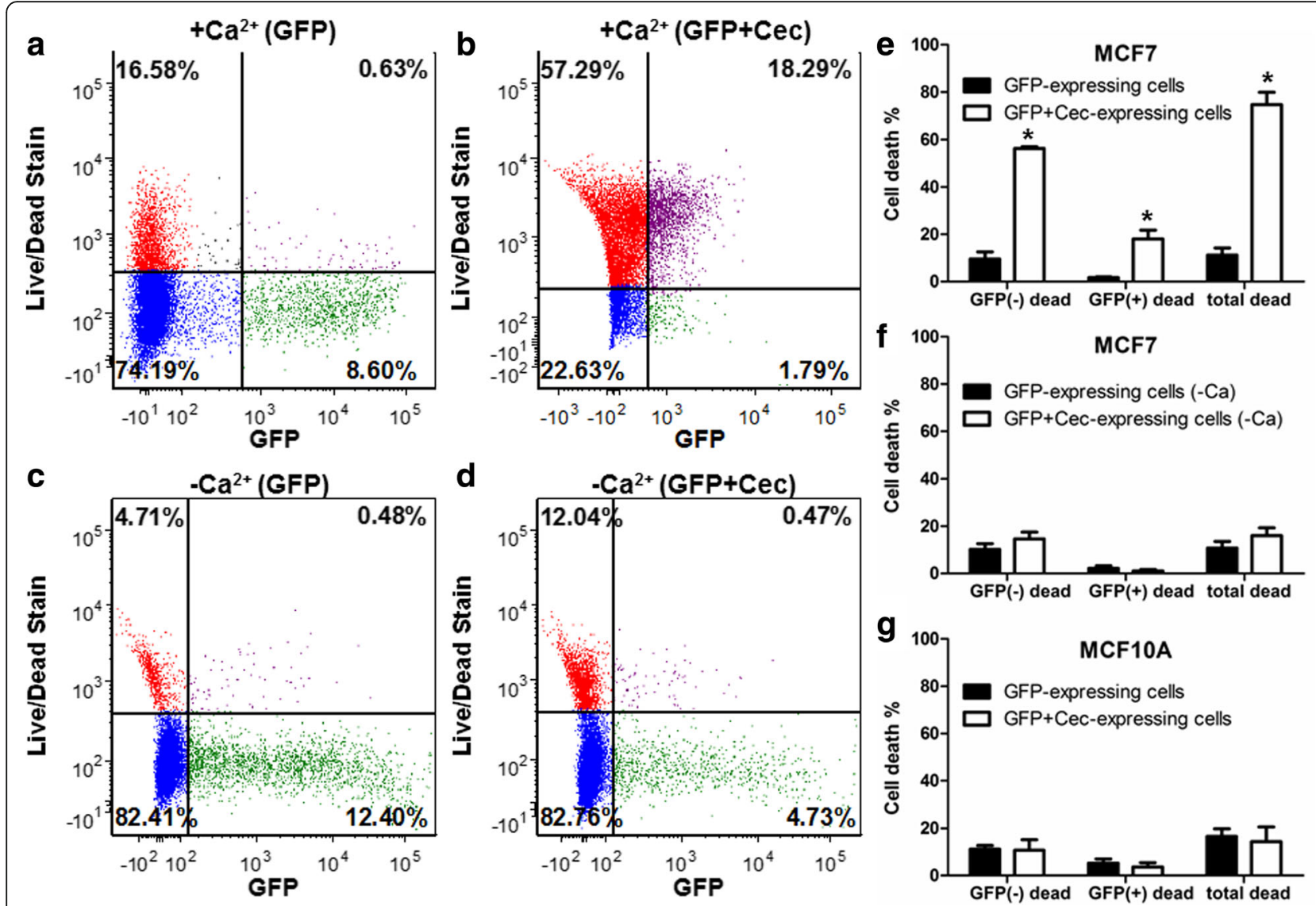

Fig. 3 Cec-induced cell death from flow cytometry. a MCF7 cells transfected with only GFP in DMEM containing 1.8 mM Ca ${ }^{2+}$. b MCF7 cells co-transfected with GFP and Cec in DMEM containing $1.8 \mathrm{mM} \mathrm{Ca}^{2+}$. c MCF7 cells transfected with only GFP in DMEM without Ca ${ }^{2+}$. d MCF7 cells co-transfected with GFP and Cec in DMEM without $\mathrm{Ca}^{2+}$. e Percentage of dead cells between GFP-expressing and Cec-expressing MCF7 groups in the presence of $\mathrm{Ca}^{2+},{ }^{*}$ indicates $p<0.001$ in all three groups $(n=6)$. $\mathbf{f}$ Percentage of dead cells between GFP-expressing and Cec-expressing MCF7 groups in the absence of $\mathrm{Ca}^{2+}, p>0.05$ in all three groups $(n=5)$. $\mathbf{g}$ Percentage of dead cells between GFP-expressing and Cec-expressing MCF10A cells, $p>0.05$ in all three groups $(n=5)$

tumor volume was $37 \%$ smaller in the treatment group than in the control group (control: $1240 \pm 379 \mathrm{~mm}^{3}, n=3$, treatment: $\left.776 \pm 112 \mathrm{~mm}^{3}, n=5, p<0.05\right)$ (5a). From week 4 to week 5 , the tumor grew by $158 \%$ in control group (week 4: $480 \pm 251 \mathrm{~mm}^{3}$, week 5: $1240 \pm 379 \mathrm{~mm}^{3}$, $n=3, p<0.05)$, whereas the tumors grew $46 \%$ in the treatment group (week 4: $533 \pm 146 \mathrm{~mm}^{3}$, week 5: $776 \pm$ $111 \mathrm{~mm}^{3}, n=5, p<0.05$ ) (5a). Over 3 -fold slower growth in treatment group was due to the smaller change in volume compared to control group from the previous week (for difference between week 4 and week 5 , control $=760 \mathrm{~mm}^{3}$; treatment $\left.=243 \mathrm{~mm}^{3}\right)(5 \mathrm{~b})$.

\section{Cec-induced cell death within MDA-MB-231 xenograft}

Hematoxylin \& eosin (H\&E) staining was performed for Cec-treated (6a) and control (6b) tumors. Close to $23 \%$ of area within the control tumors was dead $(22.6 \pm$ $15.2 \%, n=4)$ and nearly $76 \%$ of area within the treated tumors was dead $(75.7 \pm 5.3 \%, n=4)(6 \mathrm{c})$.
Concerning naturally occurred necrosis in large tumors (defined as the volume greater than $200 \mathrm{~mm}^{3}$, length greater than $7 \mathrm{~mm}$ ), we also examined dead or dying cells in small tumors (defined as the volume less than $200 \mathrm{~mm}^{3}$, length less than $7 \mathrm{~mm}$ ). Nitro blue tetrazolium (NBT) staining indicated that dead/dying cells were visible in a typical small tumor injected with Ceccontaining lentivirus (6d, dash yellow line), but barely detected in the small tumor injected with control lentivirus (6e). Although the average tumor volume was similar between the two groups (V_treat $=164.1 \pm 90.0 \mathrm{~mm}^{3}$, V_control $\left.=132.9 \pm 131.6 \mathrm{~mm}^{3}, n=3, p>0.05\right)$, the percent growth of tumor is 7 -fold smaller in treat group $(26.7 \pm 23.9 \%)$ than in control group $(201.5 \pm 123.8 \%)$ (6 F, $n=3, p<0.05$ ).

Excessive $\mathrm{Ca}^{2+}$ influx induced by Cec can trigger apoptosis commonly mediated by caspase activation [9]. Among several caspases present in the MDA-MB-231 cells, caspase- 3 is the most commonly activated one in 


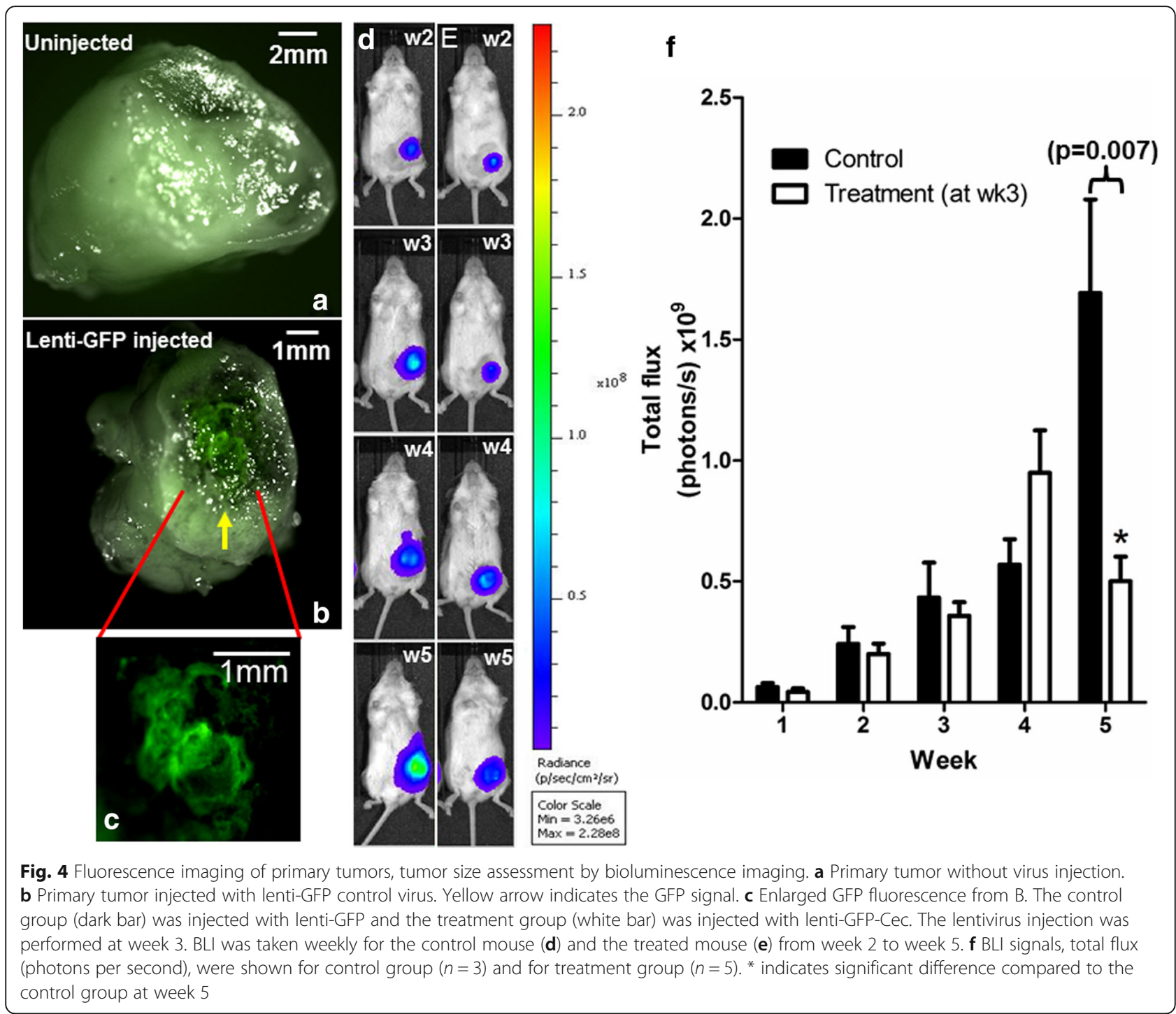

response to a variety of anti-cancer drugs that induce cell death [29-31]. The active caspase-3 protein expression was detected only in MDA-MB-231 cells expressing $\mathrm{Cec}$, but absent in cells expressing control vector (GFP) and untransfected $(\mathrm{N})$ cells (6 g). In small MDA-MB231 xenograft tumors, the cleaved (active) caspase-3 expressing cells was barely detected $(5.4 \pm 3.0 \%$ in untreated and $14.3 \pm 4.0 \%$ GFP treated group, respectively, $n=4)(6 \mathrm{~h}, \mathrm{j})$, but significantly expressed in Cec-treated group $(50.4 \pm 19.0 \%, n=4)(6 i, j)$.

\section{Discussion}

Excessive negative charges at the external surface of plasma membranes due to lower $\mathrm{K}^{+}$concentration and higher $\mathrm{Na}^{+}$concentration in cancer cells was observed nearly 50 years ago $[32,33]$. As a result, the resting plasma membrane potential is depolarized in cancer cells. The intrinsic link between membrane depolarization and tumorigenesis has been elegantly illustrated by mitosis in mature neurons induced by sustained depolarization [34].

Depolarization can activate a variety of ion channels that elicit multiple cell functions. One of these ion channels is a voltage-gated calcium channel [20]. $\mathrm{Ca}^{2+}$ influx following the opening of VGCC is a critical signal for cell proliferation [9]. Recently, membrane depolarization has been recognized as an early bioelectric signal which can serve as a diagnostic marker for cancer development, as hyperpolarization was shown to inhibit tumor formation [35].

We found a significant membrane depolarization in MCF7 and MDA-MB-231 cells compared to normal HMEC, in agreement with previous observations both in cell lines and primary tumors [5]. It is noted that use of whole-cell patch clamp technique offers advantages over microelectrode measurement of tissue for accurate measurements of plasma membrane potential [36]. We also 


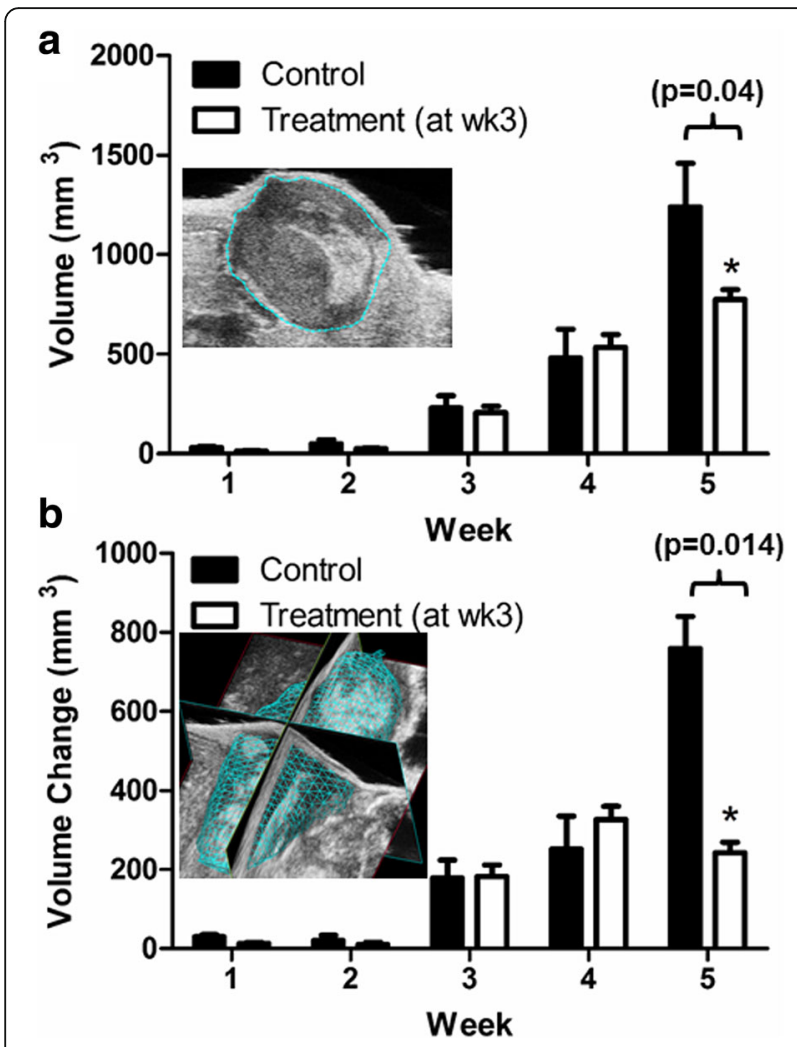

Fig. 5 Tumor volume weekly measured by ultrasound imaging. The lentivirus injection was performed at week 3. The control group (dark bar) was injected with lenti-GFP and the treatment group (white bar) was injected with lenti-GFP-Cec. Tumor volume is shown in (a) and tumor volume change is shown in (b). The inset in (a) shows the drawing contour of the tumor, the inset in (b) shows the 3D reconstitution of the tumor. The volume change was calculated by $d V(n)=V n-V(n-1)$, where $n=1$ to 5 . Data were averaged from 3 control mice and 5 treated mice. ${ }^{*}$ indicates significant difference compared to the control group at week 5

found no voltage-gated calcium currents in normal mammary epithelial cells, but T-type calcium currents in MCF7 cells with a typical voltage-dependent activation from $-70 \mathrm{mV}$ to $+40 \mathrm{mV}$ (Figs. 1c, d). These results support the notion that T-type calcium current serves as a functional biomarker in human breast cancer cells.

To test our hypothesis for selectively killing of breast cancer cells by inducing excessive $\mathrm{Ca}^{2+}$ influx, we chose Cav1.2 because it is not present in either HMEC or MCF7 cells [11, 37] (Fig. 1b). Cav1.2 began to activate at a membrane potential more positive than $-40 \mathrm{mV},+30 \mathrm{mV}$ more positive than T-type calcium current activation threshold. Thus, introducing Cav1.2 into cells should not alter cell function unless the cell is depolarized to $-40 \mathrm{mV}$.

In comparison to Cav1.2, Cec has a similar activation threshold (Fig. 1h) but the inactivation current trace was unable to return to baseline (Fig. 1g), leading to defective closure of the channel. As a result, external calcium ions can constantly enter the cell. For a $500 \mathrm{~ms}$ depolarizing pulse, opening of $\mathrm{Cec}$ channels allowed more than a 50,000 -fold higher amount of calcium influx compared to T-type calcium channels (Fig. 1j). We noted that Cav1.2 channels can also induce more than a 20,000-fold higher amount of calcium influx over T-type calcium channels (Fig. 1j). The difference between Cav1.2 and Cec, however, is that Cav1.2 channels can close (becoming inactivated) during sustained membrane depolarization, while Cec cannot.

At single-cell level, we showed that the Cec-expressing cells died when the membrane was held at $-10 \mathrm{mV}$ for an hour (Fig. 2d-f). Neighboring Cec-expressing cells that were not depolarized to $-10 \mathrm{mV}$ did not die (Fig. 2b, f). This experiment demonstrated the selectivity of Cecmediated killing of cancer cells. It also revealed difficulty in killing cancer cells expressing the Cav1.2 channel (Fig. 2g-i). Although opening of Cav1.2 can induce more than a 20,000-fold amount of $\mathrm{Ca}^{2+}$ influx compared to non-Cav1.2 expressing cells, the cells did not die due to inactivation of the channel.

The killing of MCF7 cells via a Cec-induced increase in $\mathrm{Ca}^{2+}$ influx was further tested in cell monolayer. Flow cytometry data (Fig. 3) confirmed that Cec activation can indeed kill MCF7 cells but not MCF10A cells and that $\mathrm{Ca}^{2+}$ is the critical factor in Cec-mediated cell death

To verify whether the results obtained in vitro work in vivo, we injected $1-2 \times 10^{6}$ MDA-MB-231/Luc cells into 6-8 weeks old female NSG mice. Primary tumor can grow to $0.1-0.3 \mathrm{~mm}^{3}$ volumes after $2-3$ weeks, which allows direct injection of virus into the primary tumor (Fig. 3a-c). The tumor volumes were assessed and measured by bioluminescence and ultrasound imaging, respectively. There is a noticeable difference in tumor measurements using BLI and USI. Two weeks after virus injection (at week 3), BLI showed a decrease in tumor size (Fig. 4f), whereas USI showed continuing growth of the tumors (although at a slower rate) (Fig. 5b). This difference may be due to two different imaging mechanisms. BLI signals depend on luciferin binding to luciferase in MDA-MB-231 tumor cells. Dead or dying cells cannot yield BLI signals due to disrupted luciferase structure, but they contribute to the aggregate anatomical structure captured by USI. Nevertheless, both BLI and USI measurements demonstrated consistent results: comparing to the control mice, tumor growth in the treatment group was significantly inhibited by Cec. This conclusion is further confirmed by histological examination demonstrating that the Cec-induced inhibition of tumor growth was a direct consequence of markedly increased cells death within the tumor (Fig. 6).

Apoptosis is most commonly mediated by caspase activation [9]. MDA-MB-231 cells have at least four 

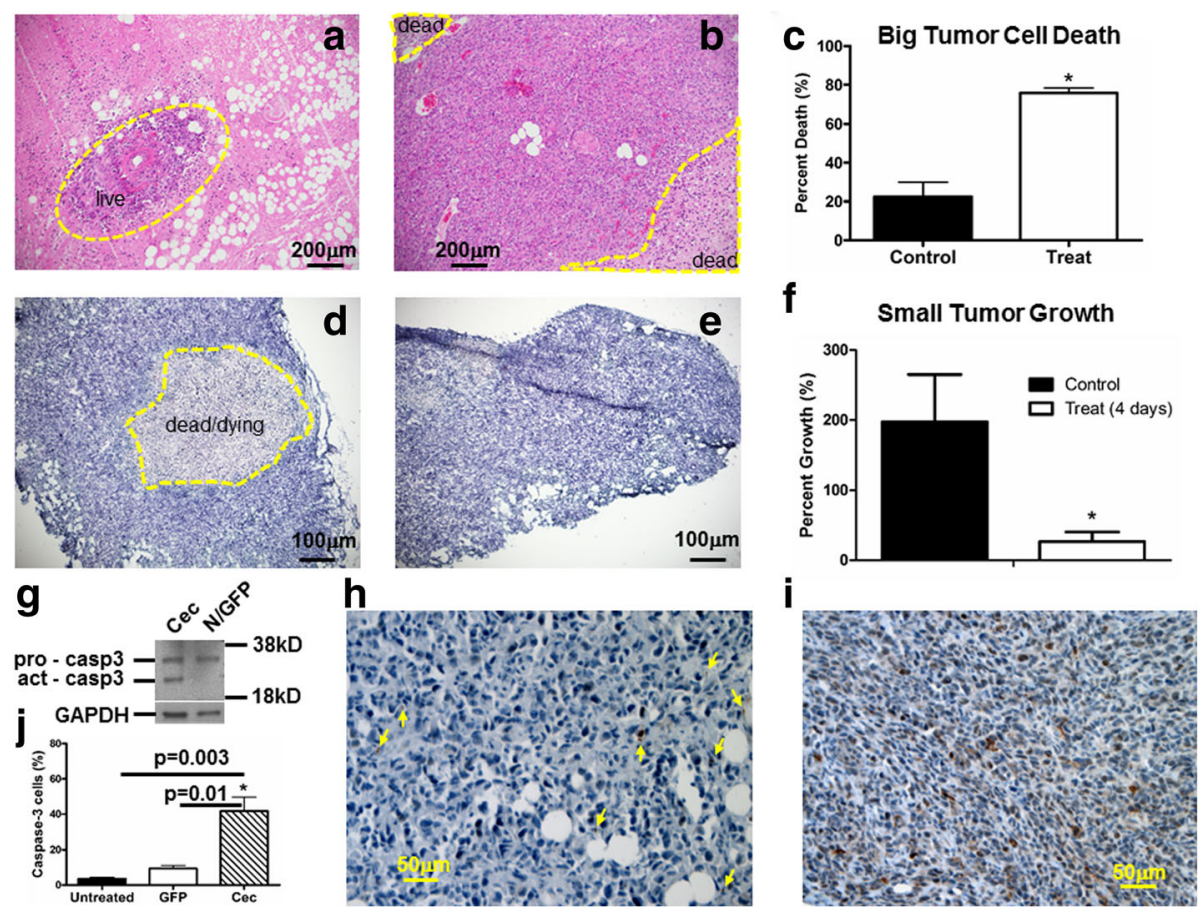

Fig. 6 Cec-induced cell death in NSG tumors. Tumors at week 6 were removed. H\&E staining was performed in a treated tumor (a) and a control tumor (b). c Percentage of dead cells in control and treat mice. Tumors at week 3.5 were removed. Live/dead NBT (nitro blue tetrazolium) staining was performed in a treated tumor (d) and in a control tumor (e). Yellow dash line indicates live (a) or dead cells (b, d). $\mathbf{f}$ Percent growth of treated and control tumors. * indicates statistical significance in comparison to the control tumor. $\mathbf{g}$ The pro-caspase was detected in MDA-MB-231 cells near $36 \mathrm{kDa}$ ( $\mathrm{N}$ for non-transfection). The active caspase appeared around $20 \mathrm{kDa}$ in cells expressing Cec but not GFP (another negative control) or non-transfection (N). GAPDH was used as the loading controls. Cleaved caspase-3 expression (cells in brown color) is shown in untreated small tumor (yellow arrows) (h) and in Cec-treated small tumor (i), respectively. j Percentage of caspase-3 expression cells in untreated or treated with empty lentiviral vector and Cec-treated small tumors. * indicates statistical significance comparing to untreated or GFP treated tumor

isoforms of caspases (caspase-3, -6, -8, -9) [31]. We found that the activated caspase- 3 expression was detected only cells expressing Cec (Fig. 6g), in agreement with a high prevalence of cleaved caspase- 3 in MDAMB-231 xenograft tumors treated by Cec (Figs. 6i, j). Thus, the Cec-induced cell death is at least partially medicated by activation of caspase- 3 .

\section{Limitations of this research in clinical perspective}

This work was focused on proof-of-concept of finding a way to treat breast cancer independent of subtypes. It is imperative to point out the limitations of this research in clinical implication. Calcium influx is a vital signal in many physiological activities such as neuronal action potential, heartbeat, and muscle contraction. Disruption of delicate intracellular calcium concentration can cause mental, cardiac, and muscle disorders. Thus, this research can only be applied locally in mammary tissue to avoid global adverse effects. Additionally, efficiency of introducing Cec into mammary epithelial cells in vivo has yet to be tested, although in cell culture lentiviral particles that contain Cec can achieve over 95\% transfection rate. These limitations are the driving forces in future direction of this research.

\section{Conclusions}

In conclusion, we presented data that supports a new strategy for selectively triggering tumor cell death: excessive $\mathrm{Ca}^{2+}$ influx induced only in the depolarized plasma membranes of breast cancer cells. This strategy is independent of subtypes of breast cancer and may have a therapeutic application in triple-negative breast cancer that currently lacks targeted therapies.

\footnotetext{
Abbreviations

BLI: Bioluminescent imaging; Cec: Engineered voltage-gated L-type calcium channel; Em: Resting membrane potential; HMEC: Human mammary epithelial cell; IHC: Immunohistochemistry; MCF10A: Human non-tumor mammary epithelial cell; MCF7: Human breast cancer cell line; MDA-MB-231: Human triple-negative breast cancer cell line; USI: Ultrasound imaging; WB: Western blot
}

\section{Acknowledgements}

The authors are grateful to Dr Jun Liu at WVU for initial discussion and for providing MCF7 and HMEC cells. MDA-MB-231/Luc cells were kindly provided by Dr. Robert Wysolmerski at WVU. The engineered L-type calcium channel, Cec, was a generous gift from Dr. Gerald Zamponi (University of Calgary). 


\section{Funding}

This work is supported by National Institute of General Medical Sciences of the National Institutes of Health (U54GM104942, P20 GM103434), American Heart Association Grant-in-Aid (13GRNT16420018), and a Research Development Grant from Health Sciences Center of West Virginia University to HY. The WVU Flow Cytometry Core is supported by Mary Babb Randolph Cancer Center CoBRE grant (GM103488/RR032138), Fortess S10 grant (OD016165), and West Virginia INBRE grant (GM103434). Animal imaging experiments and image analysis were performed in the West Virginia University Microscope Imaging Facility, supported in part by Mary Babb Randolph Cancer Center and National Institutes of Health grant P20 RR016440.

\section{Availability of data and materials}

The datasets during and/or analyzed during the current study are available from the corresponding author on reasonable request.

\section{Authors' contributions}

All authors have read and approve of the final version of the manuscript. HY developed the idea, designed and performed electrophysiological and imaging experiments, analyzed the data, and drafted the manuscript. SM and AA performed NSG mice experiments, analyzed the data, prepared the figures and provided valuable opinions in manuscript. MN performed immunoblotting and imaging experiments, analyzed the results, prepared the figures and provided editing in manuscript. KB designed and performed flow cytometry experiments, analyzed the data, prepared the figure, and participated in drafting the manuscript. KM participated in the design of tumor histological experiments and provided critical suggestions to improve the experimental design and finalization of the manuscript. JC provided histological staining, performed immunohistochemistry experiments, prepared slides, and provided interpretation of staining results and critical revision of the manuscript.

\section{Competing interests}

The authors declare that they have no competing interests.

\section{Consent for publication}

Not applicable.

\section{Ethics approval and consent to participate}

Animals used in this study are in adherence to the NIH Guide for the Care and Use of Laboratory Animals (eighth edition, 2011). All experimental protocols were approved by the Institutional Animal Care and Use Committee at West Virginia University.

\section{Author details}

${ }^{1}$ Department of Physiology and Pharmacology, West Virginia University, One Medical Center Drive, Morgantown, WV 26506, USA. ${ }^{2}$ Mary Babb Randolph Cancer Center, West Virginia University, Morgantown, WV 26506, USA. ${ }^{3}$ Department of Microbiology, Immunology and Cell Biology, West Virginia University, Morgantown, WV 26506, USA. ${ }^{4}$ Department of Neurobiology and Anatomy, West Virginia University, Morgantown, WV 26506, USA.

${ }^{5}$ Department of Pathology, West Virginia University, Morgantown, WV 26506, USA.

Received: 27 October 2016 Accepted: 2 March 2017 Published online: 04 March 2017

\section{References}

1. Higgins MJ, Baselga J, xE: Targeted therapies for breast cancer. The Journal of Clinical Investigation 2011, 121(10):3797-3803

2. Levin M. Molecular bioelectricity in developmental biology: new tools and recent discoveries: control of cell behavior and pattern formation by transmembrane potential gradients. Bioessays. 2012;34(3):205-17.

3. Singh B, Smith CW, Hughes R. In vivo dielectric spectrometer. Med Biol Eng Comput. 1979;17(1):45-60.

4. Chaudhary SS, Mishra RK, Swarup A, Thomas JM. Dielectric properties of normal \& malignant human breast tissues at radiowave \& microwave frequencies. Indian J Biochem Biophys. 1984;21(1):76-9.

5. Marino AA, Iliev IG, Schwalke MA, Gonzalez E, Marler KC, Flanagan CA. Association between cell membrane potential and breast cancer. Tumour Biol. 1994;15(2):82-9.
6. Azimi I, Roberts-Thomson SJ, Monteith GR. Calcium influx pathways in breast cancer: opportunities for pharmacological intervention. Br J Pharmacol. 2014;171(4):945-60

7. Badou A, Jha MK, Matza D, Flavell RA. Emerging roles of L-type voltage-gated and other calcium channels in T lymphocytes. Front Immunol. 2013;4:243.

8. Capiod T. Cell proliferation, calcium influx and calcium channels. Biochimie. 2011;93(12):2075-9.

9. Orrenius S, Zhivotovsky B, Nicotera P. Regulation of cell death: the calciumapoptosis link. Nat Rev Mol Cell Biol. 2003;4(7):552-65.

10. Catterall WA, Perez-Reyes E, Snutch TP, Striessnig J. International Union of Pharmacology. XLVIII. Nomenclature and structure-function relationships of voltage-gated calcium channels. Pharmacol Rev. 2005;57(4):411-25.

11. Taylor JT, Zeng XB, Pottle JE, Lee K, Wang AR, Yi SG, Scruggs JA, Sikka SS, Li M. Calcium signaling and T-type calcium channels in cancer cell cycling. World J Gastroenterol. 2008;14(32):4984-91.

12. Pera E, Kaemmerer E, Milevskiy MJ, Yapa KT, O'Donnell JS, Brown MA, Simpson F, Peters AA, Roberts-Thomson SJ, Monteith GR. The voltage gated $\mathrm{Ca}(2+)$-channel Cav3.2 and therapeutic responses in breast cancer. Cancer Cell Int. 2016;16:24.

13. Asaga $S$, Ueda M, Jinno $H$, Kikuchi K, Itano O, Ikeda T, Kitajima M. Identification of a new breast cancer-related gene by restriction landmark genomic scanning. Anticancer Res. 2006;26(1A):35-42.

14. Taylor JT, Huang L, Pottle JE, Liu K, Yang Y, Zeng X, Keyser BM, Agrawal KC, Hansen JB, Li M. Selective blockade of T-type Ca2+ channels suppresses human breast cancer cell proliferation. Cancer Lett. 2008; 267(1):116-24.

15. Stotz SC, Zamponi GW. Structural determinants of fast inactivation of high voltage-activated $\mathrm{Ca}(2+)$ channels. Trends Neurosci. 2001;24(3):176-81.

16. Zamponi GW, Snutch TP. Advances in voltage-gated calcium channel structure, function and physiology. Biochim Biophys Acta. 2013;1828(7):1521.

17. Schanne FA, Kane AB, Young EE, Farber JL. Calcium dependence of toxic cell death: a final common pathway. Science. 1979;206(4419):700-2.

18. Trump BF, Berezesky IK. Calcium-mediated cell injury and cell death. FASEB J. 1995:9(2):219-28.

19. An M, Zamponi G: Voltage-Dependent Inactivation of Voltage Gated Calcium Channels. In: Voltage-Gated Calcium Channels. Edited by Zamponi G: Eurekah.com and Kluwer Academic/Plenum Publishers; 2005: 194-204.

20. Catterall WA. Voltage-gated calcium channels. Cold Spring Harb Perspect Biol. 2011;3(8):a003947.

21. Berzingi $\mathrm{S}$, Newman $\mathrm{M}, \mathrm{Yu} \mathrm{H}-\mathrm{G}$. Altering bioelectricity on inhibition of human breast cancer cells. Cancer Cell Int. 2016;16(1):72.

22. Stotz SC, Zamponi GW. Identification of inactivation determinants in the domain IIS6 region of high voltage-activated calcium channels. J Biol Chem. 2001:276(35):33001-10.

23. Lin Y-C, Huang J, Kan H, Castranova V, Frisbee JC, Yu H-G. Defective calcium inactivation causes long QT in obese insulin-resistant rat. Am J Physiol Heart Circ Physiol. 2012;302(4):H1013-22

24. Lossi L, Alasia S, Salio C, Merighi A. Cell death and proliferation in acute slices and organotypic cultures of mammalian CNS. Prog Neurobiol. 2009; 88(4):221-45.

25. Schneider CA, Rasband WS, Eliceiri KW. NIH Image to ImageJ: 25 years of image analysis. Nat Methods. 2012;9(7):671-5.

26. Hoehn K, Watson TW, MacVicar BA. Multiple types of calcium channels in acutely isolated rat neostriatal neurons. J Neurosci. 1993;13(3):1244-57.

27. Gavilan E, Sanchez-Aguayo I, Daza P, Ruano D. GSK-3[beta] signaling determines autophagy activation in the breast tumor cell line MCF7 and inclusion formation in the non-tumor cell line MCF10A in response to proteasome inhibition. Cell Death Dis. 2013;4:e572.

28. Chavez KJ, Garimella SV, Lipkowitz S. Triple negative breast cancer cell lines: one tool in the search for better treatment of triple negative breast cancer. Breast Dis. 2010;32(1-2):35-48.

29. Lee JH, Li YC, Ip SW, Hsu SC, Chang NW, Tang NY, Yu CS, Chou ST, Lin SS, Lino CC, et al. The role of $\mathrm{Ca} 2+$ in baicalein-induced apoptosis in human breast MDA-MB-231 cancer cells through mitochondria- and caspase-3dependent pathway. Anticancer Res. 2008;28(3A):1701-11.

30. Yang $S$, Zhou Q, Yang X. Caspase-3 status is a determinant of the differential responses to genistein between MDA-MB-231 and MCF-7 breast cancer cells. Biochim Biophys Acta. 2007:1773(6):903-11.

31. Cheah YH, Nordin FJ, Tee T, Azimahtol HL, Abdullah NR, Ismail Z. Antiproliferative property and apoptotic effect of xanthorrhizol on MDAMB-231 breast cancer cells. Anticancer Res. 2008;28(6A):3677-89. 
32. Cone Jr CD. Variation of the transmembrane potential level as a basic mechanism of mitosis control. Oncology. 1970;24(6):438-70.

33. Cone $\mathrm{Jr} \mathrm{CD}$. The role of the surface electrical transmembrane potential in normal and malignant mitogenesis. Ann N Y Acad Sci. 1974;238:420-35.

34. Cone $\mathrm{Jr} C \mathrm{CD}$, Cone CM. Induction of mitosis in mature neurons in central nervous system by sustained depolarization. Science. 1976;192(4235):155-8.

35. Chernet BT, Levin M. Transmembrane voltage potential is an essential cellular parameter for the detection and control of tumor development in a Xenopus model. Dis Model Mech. 2013;6(3):595-607.

36. Neher E, Sakmann B, Steinbach JH. The extracellular patch clamp: a method for resolving currents through individual open channels in biological membranes. Pflugers Arch. 1978;375(2):219-28.

37. Pottle J, Sun C, Gray L, Li M. Exploiting MCF-7 Cells' calcium dependence with interlaced therapy. J Cancer Ther. 2013;4(7A):32-40.

Submit your next manuscript to BioMed Central and we will help you at every step:

- We accept pre-submission inquiries

- Our selector tool helps you to find the most relevant journal

- We provide round the clock customer support

- Convenient online submission

- Thorough peer review

- Inclusion in PubMed and all major indexing services

- Maximum visibility for your research

Submit your manuscript at www.biomedcentral.com/submit
Biomed Central 